\title{
Article \\ Genetic Manipulation of the Brassicaceae Smut Fungus Thecaphora thlaspeos
}

\author{
Lesley Plücker ${ }^{\dagger}$, Kristin Bösch ${ }^{\dagger}$, Lea Geißl, Philipp Hoffmann and Vera Göhre *D \\ Institute of Microbiology, Cluster of Excellence in Plant Sciences, Heinrich-Heine University, Building 26.24.01, \\ Universitätsstr.1, 40205 Düsseldorf, Germany; lesley.pluecker@hhu.de (L.P.); kristin.boesch@hhu.de (K.B.); \\ lea.geissl@hhu.de (L.G.); Philipp.Hoffmann.15@uni-duesseldorf.de (P.H.) \\ * Correspondence: vera.goehre@hhu.de; Tel.: +49-211-811-1529 \\ t These authors contribute equally to this work.
}

check for updates

Citation: Plücker, L.; Bösch, K.; Geißl, L.; Hoffmann, P.; Göhre, V. Genetic Manipulation of the Brassicaceae Smut Fungus Thecaphora thlaspeos. J. Fungi 2021, 7, 38. https://doi.org/10.3390/jof7010038

Received: 16 November 2020 Accepted: 7 January 2021 Published: 9 January 2021

Publisher's Note: MDPI stays neutral with regard to jurisdictional clai$\mathrm{ms}$ in published maps and institutional affiliations.

Copyright: (C) 2021 by the authors. Licensee MDPI, Basel, Switzerland. This article is an open access article distributed under the terms and conditions of the Creative Commons Attribution (CC BY) license (https:// creativecommons.org/licenses/by/ $4.0 /)$.

\begin{abstract}
Investigation of plant-microbe interactions greatly benefit from genetically tractable partners to address, molecularly, the virulence and defense mechanisms. The smut fungus Ustilago maydis is a model pathogen in that sense: efficient homologous recombination and a small genome allow targeted modification. On the host side, maize is limiting with regard to rapid genetic alterations. By contrast, the model plant Arabidopsis thaliana is an excellent model with a vast amount of information and techniques as well as genetic resources. Here, we present a transformation protocol for the Brassicaceae smut fungus Thecaphora thlaspeos. Using the well-established methodology of protoplast transformation, we generated the first reporter strains expressing fluorescent proteins to follow mating. As a proof-of-principle for homologous recombination, we deleted the pheromone receptor pra1. As expected, this mutant cannot mate. Further analysis will contribute to our understanding of the role of mating for infection biology in this novel model fungus. From now on, the genetic manipulation of $T$. thlaspeos, which is able to colonize the model plant $A$. thaliana, provides us with a pathosystem in which both partners are genetically amenable to study smut infection biology.
\end{abstract}

Keywords: mating; pheromone receptor; homologous recombination; infection; smut; transformation; protoplast

\section{Introduction}

Smut fungi are important pathogens causing economic losses in crops such as barley, wheat, maize, and potato [1]. The dimorphic lifecycle of grass smut fungi is comprised of a yeast form [2] that, in contrast to many other biotrophic fungi, can be cultured, and is amenable to genetic manipulation [3]. In combination with the efficient homologous recombination, this has turned Ustilago maydis, the maize smut fungus [4], into an important model organism for fungal and infection biology [5,6].

$U$. maydis starts the infection by mating, resulting in the morphological switch to the infectious filamentous form. Mating in smut fungi is controlled by two mating loci. The $a$ locus encodes for pheromones $(m f a)$ and pheromone receptors ( $p r a)$ that mediate recognition of compatible mating partners and trigger cell fusion [7]. The $b$ locus contains two genes $(b W, b E)$ encoding for subunits of a heterodimeric, homeodomain transcription factor. When an active transcription factor is assembled from different alleles in the common cytosol after plasmogamy, filamentous growth is initiated and thereby the fungus switches from saprophytic to pathogenic growth [8]. Notably, the infectious filaments are arrested in the cell cycle until successful penetration of the host plant [9]. This mating system is widely conserved in grass smut fungi and allows for genetic exchange between the mating partners [10].

In contrast to the well-characterized grass smut fungi infecting important monocot crop plants with $U$. maydis at the forefront, little is known about smut fungi infecting dicot plants. A reemerging example is Microbotryum that is regaining attention today [11]. 
By contrast, the Thecaphora-clade [12], with agronomically relevant members such as $T$. solani [13] or T. frezii [14] infecting potato and peanut, respectively, remains largely elusive. One member, the Brassicaceae smut fungus T. thlaspeos, infects several Arabis species [12] and can colonize Arabidopsis thaliana [15], making it a good system to study smut infection in model plants. Interestingly, germinating teliospores of $T$. thlaspeos directly give rise to an infectious filament, and no saprophytic phase is known. However, prolonged cultivation leads to fungal proliferation as filamentous, haploid cultures. From such cultures, two filamentous haploid T. thlaspeos strains of compatible mating types, LF1 and LF2, could be isolated [15]. The unique germination pattern and the emergence of haploid filaments in culture raise questions about mating and meiosis in T. thlaspeos.

The genome of T. thlaspeos was recently sequenced and annotated. With $20.5 \mathrm{Mb}, 6239$ gene models, and a low repeat content, it is a typical smut fungal genome [16]. Notably, we could identify the mating loci $a$ and $b$ in this genome. In comparison to the grass smut fungi, the $a$ locus of $T$. thlaspeos is strongly rearranged, and aligns well to the biocontrol yeast Anthracocystis flocculosa (formerly Pseudozyma flocculosa). It still contains one copy of the pheromone receptor pra 1 and pheromone $m f a 1$, or pra 2 and $m f a 2$ in T. thlaspeos LF1 and LF2, respectively [16]. The $b$ locus is conserved with a bi-directional promoter in between the two genes, and we have previously shown that the heterodimer formation of $b E$ and $\mathrm{bW}$ isconserved in T. thlaspeos [15]. Conservation of the mating genes throughout evolution suggests that $T$. thlaspeos still uses mating, e.g., for exchange of genetic material. However, the infectious lifecycle so far has not revealed a stage where mating is required. Therefore, we aimed for a more detailed understanding of the role of the $T$. thlaspeos mating genes.

To study the mating process in T. thlaspeos, genetic manipulation is essential. For example, reporter lines enable life-cell imaging, and deletion mutants can give insight into mutant phenotypes. Several transformation methods have been developed for smut fungi. Protoplast-mediated transformation is used for the grass smuts U. maydis [17], Sporisorium reilianum [18], U. hordei [19], U. esculenta [20], and U. bromivora [21], as well as the filamentous Basidiomycete Serendipita indica (formerly Piriformospora indica) [22], and the biocontrol yeast An. flocculosa [23]. Agrobacterium-mediated transformation is used for S. scitamineum in combination with a CRISPR-Cas9 system [24], and also for bringing larger fragments into $U$. hordei [25] and for gene tagging in $U$. maydis [26].

Here, we have established a protoplast-based PEG-mediated transformation system and generated targeted deletion mutants to investigate the mating process in T. thlaspeos.

\section{Materials and Methods}

\subsection{Fungal Culture Conditions}

T. thlaspeos LF1 and LF2 haploid strains [15] from our own collection were used in this study. Both were grown in YEPS light liquid medium (1\% yeast extract $w / v, 0.4 \%$ $w / v$ Bacto TM-Peptone, and $0.4 \% w / v$ sucrose) or YEPS light solid medium with $0.6 \%$ $w / v$ plant agar or $1 \% w / v$ phytagel at $18{ }^{\circ} \mathrm{C}$. Cryostocks of $T$. thlaspeos were generated by mixing exponentially growing cultures with $30 \%$ glycerol in growth medium followed by immediate freezing at $-80^{\circ} \mathrm{C}$. Filamentous cultures were started by resuspending the glycerol stock in growth medium or plating the cells on solid medium as described above.

\subsection{Plasmid Construction}

All plasmids used in this study were generated with the Golden Gate Cloning technique (Protocol S1) as described [27]. The hpt-egfp and hpt-mcherry sequences were codonoptimized for $U$. maydis. Promoter and terminator sequences from $T$. thlaspeos or $U$. maydis were amplified via PCR from genomic DNA.

\subsection{Protoplasting}

T. thlaspeos cultures were grown in YEPS light medium to an $\mathrm{OD}_{600}$ of $0.5-0.8$ for 3 to 4 days. Fungal mycelium was collected using cell strainers with $40 \mu \mathrm{m}$ mesh size (VWR TM Darmstadt, Germany) and washed with protoplasting buffer $(0.1 \mathrm{M}$ sodium citrate, $0.01 \mathrm{M}$ 
EDTA 1.2 $\mathrm{M} \mathrm{MgSO}_{4}$, and $\mathrm{pH}$ 5.8) to remove residual culture medium. T. thlaspeos tissue was resuspended in $9 \mathrm{~mL}$ protoplasting buffer, supplemented with $10 \mathrm{mg} / \mathrm{mL}$ Yatalase (Takara Bio, Kusatsu, Japan) and $20 \mathrm{mg} / \mathrm{mL}$ Glucanex (Sigma-Aldrich, St. Luis, MI, USA) per $100 \mathrm{~mL}$ cell culture, and incubated for 30-60 $\mathrm{min}$ at room temperature. Protoplast formation was controlled microscopically. When protoplasting was finished, protoplasting buffer was added to a total volume of $24 \mathrm{~mL}$. Aliquots of $6 \mathrm{~mL}$ crude protoplast solution were overlayed with $5 \mathrm{~mL}$ trapping buffer $(0.6 \mathrm{M}$ sorbitol, $0.1 \mathrm{M}$ Tris/ $\mathrm{HCl} \mathrm{pH} \mathrm{7.0)}$ and centrifuged at $4863 \times g(5000 \mathrm{rpm})$ in a swing out rotor at $4{ }^{\circ} \mathrm{C}$ for $15 \mathrm{~min}$. The interphase was collected from all tubes and diluted with 2 volumes of ice-cold STC buffer $(0.01 \mathrm{M}$ Tris $/ \mathrm{HCl} \mathrm{pH} \mathrm{7.5,} 0.1 \mathrm{M} \mathrm{CaCl}_{2}$, and $1.0 \mathrm{M}$ sorbitol). Protoplasts were pelleted at $4863 \times$ $g(5000 \mathrm{rpm})$ in a swing out rotor at $4{ }^{\circ} \mathrm{C}$ for $10 \mathrm{~min}$ and resuspended in $500 \mu \mathrm{L}$ ice-cold STC buffer. $100 \mu \mathrm{L}$ protoplast aliquots were used for transformation immediately. A bullet point version of the protocol is available with the supplementary files (Protocol S1).

\subsection{Transformation}

Transformation of T. thlaspeos protoplasts were carried out as described for $U$. maydis [28] with slight modifications. Transformation reactions were spread on YMPG-Reg $(0.3 \% w / v$ Yeast extract, $0.3 \% w / v$ malt extract, $0.5 \% w / v$ Bacto-Peptone, $1 \% w / v$ glucose, $1 \mathrm{M}$ sucrose, $0.6 \% w / v$ plant agar, Duchefa Biochemie, Haarlem, Netherlands) medium and incubated at $18{ }^{\circ} \mathrm{C}$ until colonies appeared (1-2 months). Selection was carried out on $10 \mu \mathrm{g} / \mathrm{mL}$ Hygromycin B (Roth, Karlsruhe Germany) following the layered-plate strategy used for $U$. maydis [28]. In this setup, hygromycin was provided in the bottom layer so that it took time to diffuse to the top before the selection took place. This gave protoplasts time to regenerate and express the resistance gene [28]. Colonies were singled-out on YEPS light solid medium supplemented with $10 \mu \mathrm{g} / \mathrm{mL}$ hygromycin. Single colonies were then used to inoculate YEPS light liquid cultures for molecular analysis.

\subsection{Molecular Analysis of Transformants}

Successful integration of the constructs were determined by PCR and Southern Blot analysis [28], and eGfp or mCherry fluorescence was used as a rapid indicator for expression of the constructs. Genomic DNA of T. thlaspeos was extracted using the NEB Monarch Genomic DNA Purification Kit (New England Biolabs, Frankfurt, Germany).

\subsection{Mating Assay}

For confrontation assays, liquid cultures of T. thlaspeos strains were spotted on YEPS light solid medium in close proximity and allowed to grow towards each other. When the hyphae of both strains were close enough to appear in the display window of the microscope, a time lapse experiment was conducted to monitor mating for 24-72 h.

For liquid mating assays, strains of compatible mating types were mixed in YEPS light liquid medium in equal amounts and incubated at $18{ }^{\circ} \mathrm{C}$ and $200 \mathrm{rpm}$. Medium was exchanged twice a week. After 8-14 days, plasmogamy was observed microscopically via eGfp and mCherry fluorescence.

\subsection{Microscopy}

Fluorescence microscopy as well time lapse experiments were performed on a Zeiss Axio Immager M1 according to [29]. Microscope control, image acquisition, and processing were done with the software package Meta-Morph (version 7; Molecular Devices).

\section{Results}

\subsection{Protoplast-Generation from Filamentous T. thlaspeos Cultures}

Protoplast-mediated transformation is well-established for fungi [30]. The protocol for $U$. maydis [17] was successfully adapted for other smut fungi and therefore was also the starting point for $T$. thlaspeos protoplast generation. Critical factors besides cultivation conditions are the enzyme mixture, the buffer composition, and the osmotic stabilizer. 
First, we compared different enzyme mixtures. Glucanex, a mix of lysing enzymes from Trichoderma harzianum including beta-1,3-glucanase activity, works well for U. maydis and the filamentous Basidiomycete S. indica [22]. Yatalase comprises of a mix of lysing enzymes from Corynebacterium, including chitinase-, chitobiase-, and beta-1,3-glucanase activity, for cell wall lysis of filamentous fungi. In combination with Glucanex, it is used for U. bromivora [21] and Agrocybe aegerita [31], or supplemented with chitinase for Aspergillus niger [32]. Novozyme 234, which worked very well for $U$. maydis [28], is no longer commercially available, so we did not include it in our study. In pilot studies, we compared enzyme and buffer combinations of published protoplasting protocols and found that the combination of Glucanex and Yatalase efficiently protoplasts the T. thlaspeos filaments (Table S1).

Therefore, to first optimize the osmotic stabilizer, we used this enzyme mix in the $U$. maydis protoplasting buffer. Typical osmotic stabilizers are inorganic salts, sugars, or sugar alcohols [33]. For example, sorbitol is used for $U$. maydis, and sucrose for $U$. esculenta. Thus, we tested sorbitol and sucrose, as well as $\mathrm{MgSO}_{4}$, which is used frequently in combination with Yatalase. Most protoplasts were obtained using $\mathrm{MgSO}_{4}$ (Figure 1). Notably, sorbitol and sucrose inhibited cell wall lysis, confirming early observations [34,35]. Subsequently, we tested various commonly used protoplasting buffers, in combination with $\mathrm{MgSO}_{4}$ as the osmotic stabilizer. There were no significant differences between the four tested buffers (Table 1), but we observed tendencies that citrate buffers work better for fast growing cultures that were sub-cultured bi-weekly (Figure S1). Ultimately, we decided on the $0.1 \mathrm{M}$ citrate buffer and 0.01 M EDTA, which is also the buffer used for An. flocculosa, the closest homolog of $T$. thlaspeos, and a bi-weekly splitting rhythm.
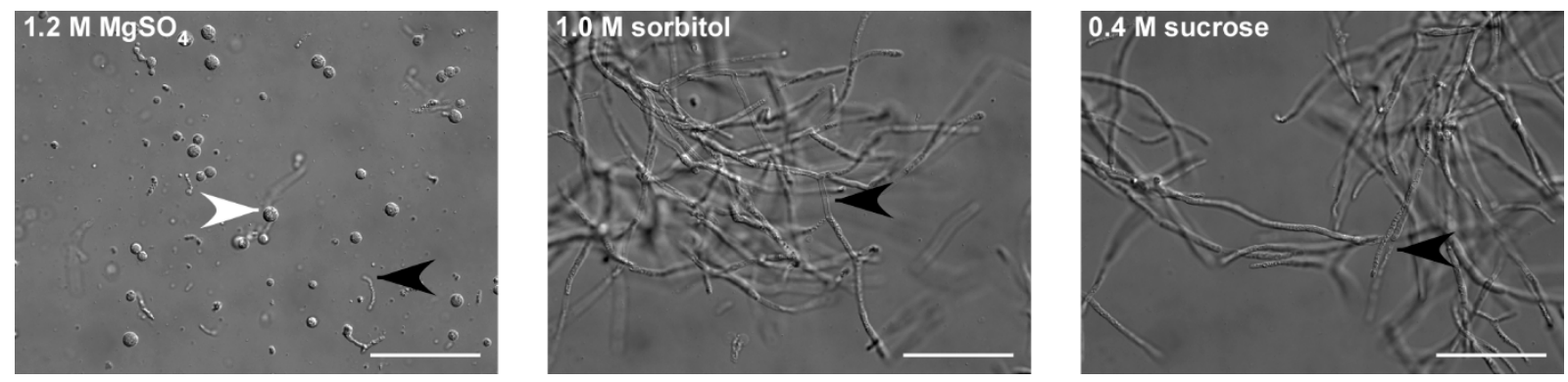

Figure 1. Identification of an osmotic stabilizer. Thecaphora thlaspeos LF1 culture was grown to an $\mathrm{OD}_{600}=0.4-0.8$. To optimize protoplasting of $T$. thlaspeos hyphae by Yatalase and Glucanex, the osmotic stabilizers $\mathrm{MgSO}_{4}$, sorbitol, and sucrose were tested. With $\mathrm{MgSO}_{4}$ as osmotic stabilizer, all filaments were digested; while in sorbitol and sucrose, no protoplasts were obtained. Black arrowheads: filaments; white arrowheads: protoplast; scale bar: $50 \mu \mathrm{m}$.

An advantage of $\mathrm{MgSO}_{4}$ as osmotic stabilizer is that the majority of intact protoplasts in the presence of $\mathrm{MgSO}_{4}$ have large vacuoles [38], which enables collection and purification, and floating in a trapping buffer [36]. Intact protoplasts accumulate in a sharp band at the interphase, and debris pellet at the bottom (Figure 2). After washing with STC buffer, up to $10^{8}$ protoplasts/g fresh weight can be recovered.

Upon determination of the optimal buffer and osmotic stabilizer, we reevaluated the composition and concentration of the enzyme mix (Figure 3). As the pilot study had indicated, for efficient degradation of the T. thlaspeos cell wall, the combined activity of Yatalse and Glucanex is necessary. As expected, individually the enzymes are poorly active, leaving filaments behind (Figure 3A). This emphasizes the importance of testing various lysing enzymes, alone and in combination, in different buffers to find a mix suitable for the organism of choice and its individual cell wall composition [30].

Finally, we aimed to decrease the enzyme concentrations to save costs. However, lowering the concentration to half resulted in incomplete digestion of the fungal cell wall after $30 \mathrm{~min}$ (Figure 3B). Since it was described earlier that a shorter incubation time is 
preferable, compared to a low enzyme concentration, regarding protoplast viability $[39,40]$, we did not reduce the enzyme concentrations.

Table 1. Optimizing the protoplasting buffer. To identify the optimal osmotic stabilizer, fungal hyphae were filtered and incubated in $0.02 \mathrm{M}$ citrate buffer, supplemented with different osmotic stabilizers and $10 \mathrm{mg} / \mathrm{mL}$ Yatalase $+20 \mathrm{mg} / \mathrm{mL}$ Glucanex, for $60 \mathrm{~min}$ at RT. Protoplasting worked only if $\mathrm{MgSO}_{4}$ was used as osmotic stabilizer. To optimize the buffer for the use of $\mathrm{MgSO}_{4}$, hyphae were filtered and incubated in different buffers, supplemented with $1.2 \mathrm{M} \mathrm{MgSO}_{4}$ and 10 $\mathrm{mg} / \mathrm{mL}$ Yatalase $+20 \mathrm{mg} / \mathrm{mL}$ Glucanex, for $60 \mathrm{~min}$ at RT. There was no significant difference between the indicated buffers, but a tendency towards higher yields with citrate buffers.

\begin{tabular}{ccc}
\hline Buffer & $\begin{array}{c}\text { Osmotic Stabilizer } \\
\text { Optimizing the Osmotic Stabilizer }\end{array}$ & ${\text { Protoplast Yield/g FW } \times \mathbf{~ 1 0}^{\mathbf{7}}}$ \\
\hline & $0.4 \mathrm{M}$ sucrose [20] & no protoplasts \\
& $1.2 \mathrm{M} \mathrm{MgSO}$ [36] & $5.52 \pm 1.22$ \\
0.02 M citrate, pH 5.8 [28] & $1.0 \mathrm{M} \mathrm{sorbitol} \mathrm{[28]}$ & $7.46 \pm 2.02$ \\
& & $7.49 \pm 1.51$ \\
0.1 M citrate, 0.01 M EDTA, pH 5.8 [23] & & $5.28 \pm 0.66$ \\
0.02 M citrate, pH 5.8 [28] & $1.2 \mathrm{M} \mathrm{MgSO}_{4}[36]$ & $5.01 \pm 0.51$ \\
0.02 M MES, pH 5.8 [21] & & \\
\hline
\end{tabular}

A

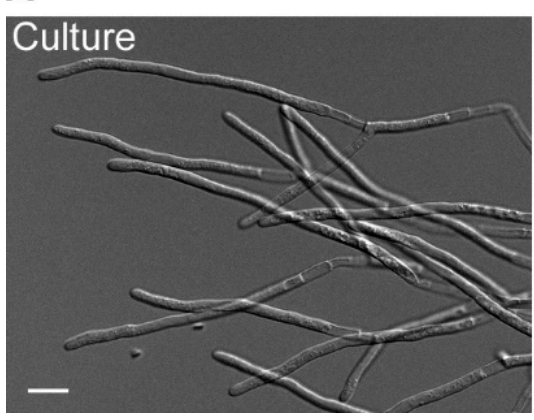

B

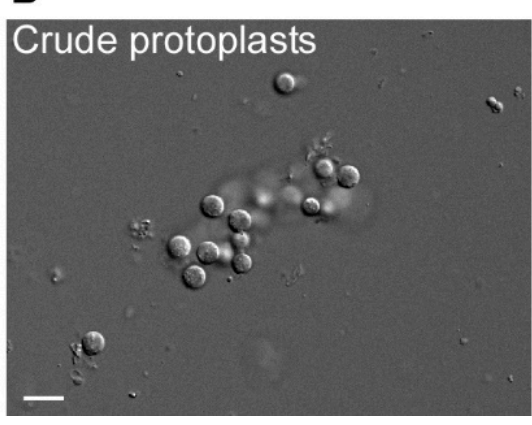

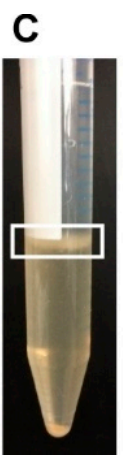

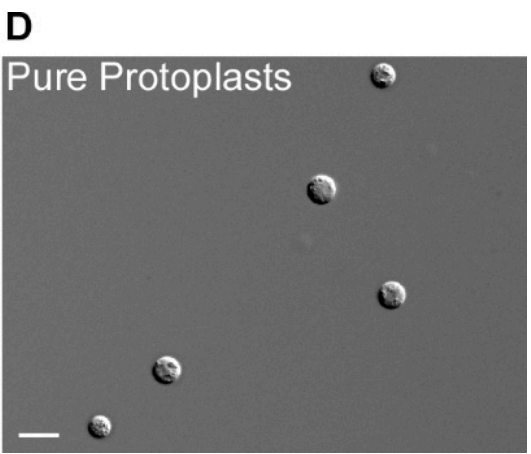

Figure 2. Protoplasting filamentous $T$. thlaspeos cultures. 1-2 g fresh weight of an exponentially growing culture (A) was harvested by filtration and protoplasted with Glucanex and Yatalase for 30-60 min. To purify the crude protoplasts (B), they are floated in a gradient (C). Filaments and debris are found in the pellet, the protoplasts can be collected from the interphase (marked with a white box). (D) An efficient protoplasting reaction results in up to $10^{8}$ protoplasts $/ \mathrm{g}$ fresh weight. Scale bar: $10 \mu \mathrm{m}$.

In contrast to other applications of protoplasts, for genetic manipulation, the protoplasts have to be viable and able to regenerate their cell wall. Thus, we next investigated the influence of the osmotic stabilizer on regeneration of the protoplasts after transformation. This allowed us to separate optimization of both steps. Using protoplasts generated in the presence of $\mathrm{MgSO}_{4}$, we assessed regeneration media containing different osmotic stabilizers such as sucrose, glucose, sorbitol, and $\mathrm{KCl}$ (Figure 4). $\mathrm{MgSO}_{4}$ was excluded due to incompatibility with the gelling agent. Maximal regeneration was obtained with $1 \mathrm{M}$ sucrose as osmotic stabilizer, followed by sorbitol and glucose, while $1 \mathrm{M} \mathrm{KCl}$ completely inhibited regeneration and fungal growth (Figure 4A). In support, T. thlaspeos LF1 cell cultures do not grow on $1 \mathrm{M} \mathrm{KCl}$, indicating that it is toxic at this concentration, while sucrose, glucose, and sorbitol only reduce the growth rate (Figure 4B). Without an osmotic stabilizer, cells were not able to regenerate, indicating that any residual filaments were efficiently removed during purification of the protoplasts (Figure 4A). U. maydis protoplasts regenerate into yeast cells and form colonies within three days [17,41]. For T. thlaspeos, we expected filaments to emerge from the protoplast, since we had never observed yeast-cells for this fungus. Furthermore, the slow growth rate of $T$. thlaspeos cultures suggests a longer 
regeneration time. To confirm our expectation, we described the regeneration process and its timing for T. thlaspeos protoplasts on regeneration medium with $1 \mathrm{M}$ sucrose. After one day, protoplasts turned dark, which is indicative of cell wall regeneration. Three to eight days later, a filament emerges from the protoplast that starts branching after 7-13 days, finally resulting in a micro-colony after 11-18 days (Figure 4C). Further proliferation leads to filamentous colonies after four to five weeks, which are indistinguishable from the original culture.

\section{A}
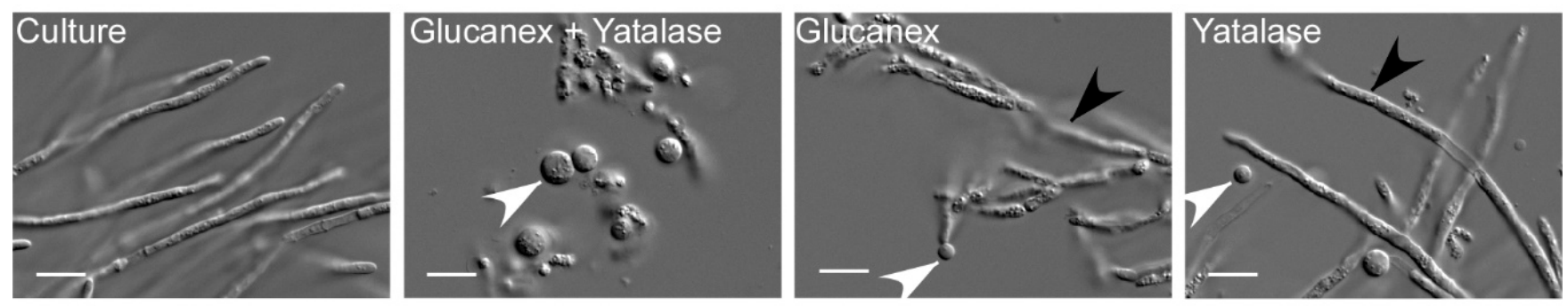

\section{B}
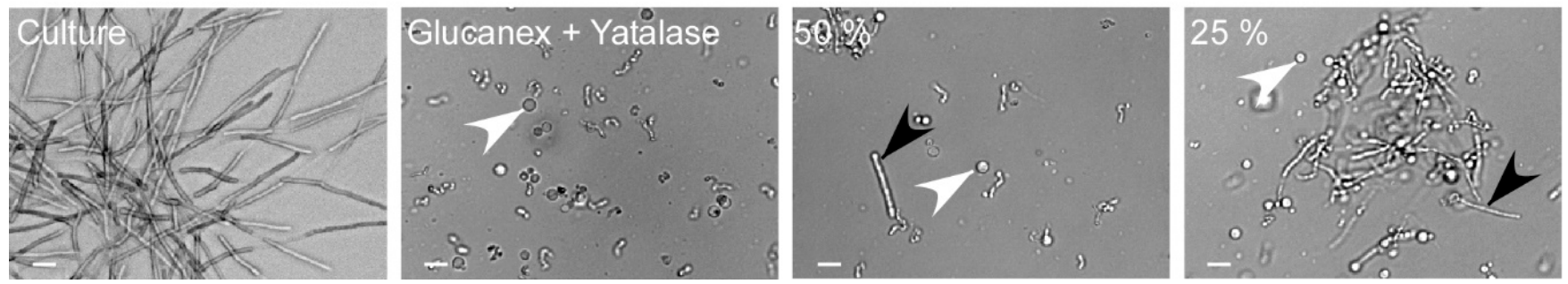

Figure 3. Optimizing the enzyme cocktail for protoplasting. (A) Filamentous cultures were harvested and incubated with a combination of $20 \mathrm{mg} / \mathrm{mL}$ Glucanex and $10 \mathrm{mg} / \mathrm{mL}$ Yatalase, or each enzyme individually, for 30 min. Protoplasting was efficient only when both enzymes were applied. (B) The enzymes were diluted to identify the lowest suitable concentration. The frequency of remaining filaments is inversely proportional to the enzyme concentration. The highest efficiency was obtained with $20 \mathrm{mg} / \mathrm{mL}$ Glucanex and $10 \mathrm{mg} / \mathrm{mL}$ Yatalase. White arrowhead: protoplasts; black arrowhead: residual filaments; scale bar: $10 \mu \mathrm{m}$.

\subsection{Transformation}

Five antibiotic resistance markers directed against phleomycin, hygromycin, nourseothricin, geneticin, and carboxin are routinely used in $U$. maydis [3]. To develop markers for T. thlaspeos, we tested culture growth on four of these antibiotics. Phleomycin is a mutagen and therefore was not considered [42]. T. thlaspeos cells were efficiently killed by the four antibiotics (Figure S2). Concentration gradients with hygromycin, nourseothricin, and carboxin revealed that $T$. thlaspeos was more sensitive towards these antibiotics than $U$. maydis. $10 \mu \mathrm{g} /$ hygromycin $\mathrm{mL}$ and $50 \mu \mathrm{g} / \mathrm{mL}$ nourseothricin efficiently killed $T$. thlaspeos hyphae. This is 20 times and three time less than the standard concentration used for $U$. maydis, respectively. By contrast, cells are less sensitive towards carboxin and remained resistant at $2 \mu \mathrm{g} / \mathrm{mL}$, the standard concentration used for $U$. maydis, but were sensitive at $100 \mu \mathrm{g} / \mathrm{mL}$. (Figure S2). Carboxin inhibits the mitochondrial succinate dehydrogenase (SDH2), and a point mutation, H253L, leads to a resistant form in $U$. maydis [43]. The $T$. thlaspeos SDH2 was highly conserved, with $82 \%$ amino acid similarity, and contained an arginine instead of the histidine at this position (Figure S3). This might explain the reduced sensitivity.

Due to the high hygromycin sensitivity, the bacterial hygromycin-phospho-transferase (hpt) [17] was used as the first resistance marker. We expressed it as a fusion protein hpt-eGfp [44] under the control of $T$. thlaspeos and $U$. maydis promoters and terminators (Table S2). Promoter activity was verified in $U$. maydis. Both $\mathrm{P}_{\text {Tthsp70 }}$ and $\mathrm{P}_{\text {Ttrps27 }}$ were 
active in $U$. maydis, and all five constructs resulted in hygromycin-resistant transformants with eGfp-fluorescence (Figure 5 and Figure S4), suggesting the constructs are functional and can be used to transform T. thlaspeos.

A
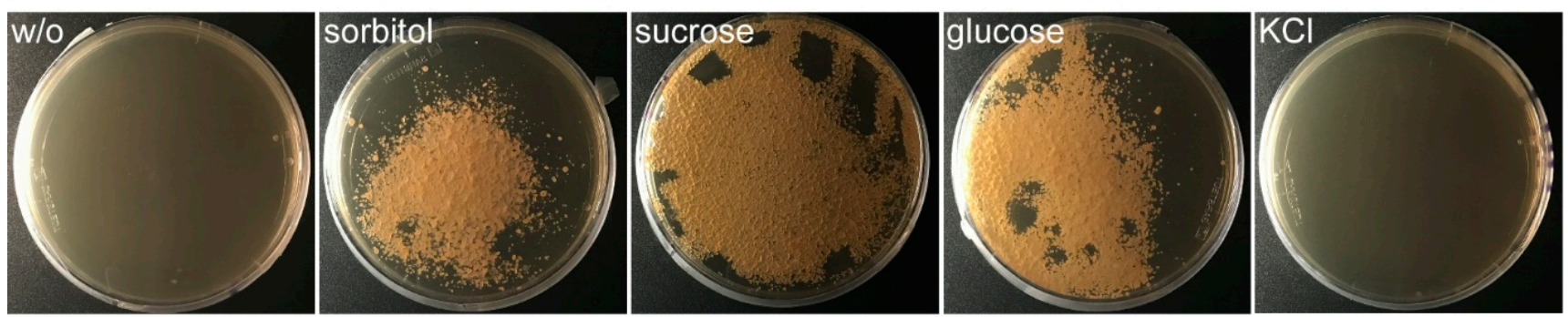

B
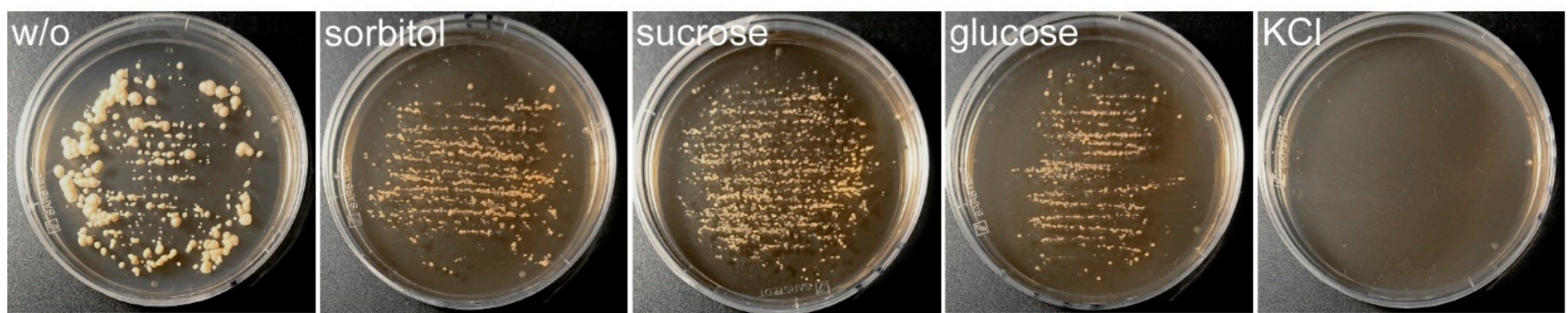

C
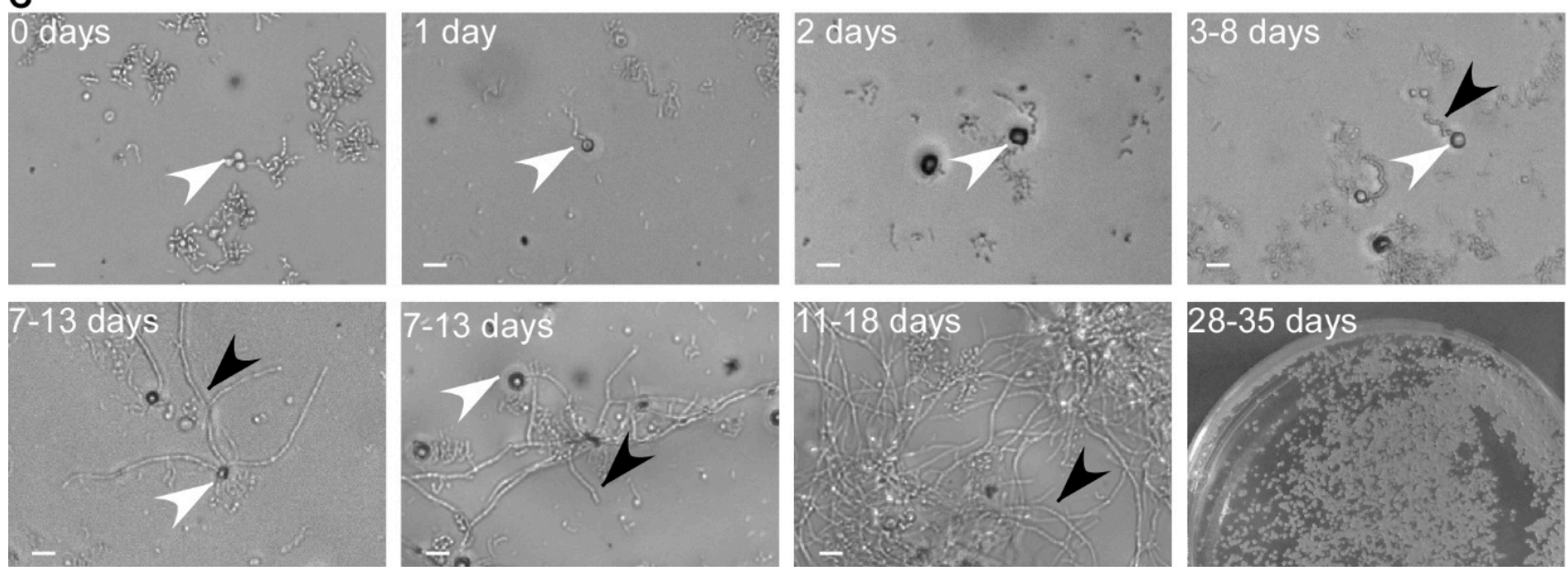

Figure 4. Optimizing protoplast regeneration. (A) Protoplasts regenerated for 39 days on regeneration medium (YMPG) with either $1 \mathrm{M}$ sorbitol, sucrose, glucose, or $\mathrm{KCl}$. No regeneration was observed without osmotic stabilizer. It was most efficient on sucrose, followed by glucose and sorbitol, while $\mathrm{KCl}$ inhibited cell growth. (B) T. thlaspeos LF1 culture plated on YMPG with sorbitol, sucrose, glucose, $\mathrm{KCl}$, or without osmotic stabilizer. After 21 days, no growth was observed for $1 \mathrm{M} \mathrm{KCl}$. Growth rate is reduced for $1 \mathrm{M}$ sorbitol, glucose, and sucrose compared to absence of osmotic stabilizer. (C) Regeneration of protoplasts on YMPG with $1 \mathrm{M}$ sucrose documented microscopically for 11-18 days. Initially, the protoplasts turned dark (2 days) before new filaments emerged (3-8 days). The filaments proliferated (11-18 days), resulting in macroscopically visible colonies (28-35 days). White arrowhead: protoplasts; black arrowhead: emerging filaments; scale bar: $10 \mu \mathrm{m}$. 

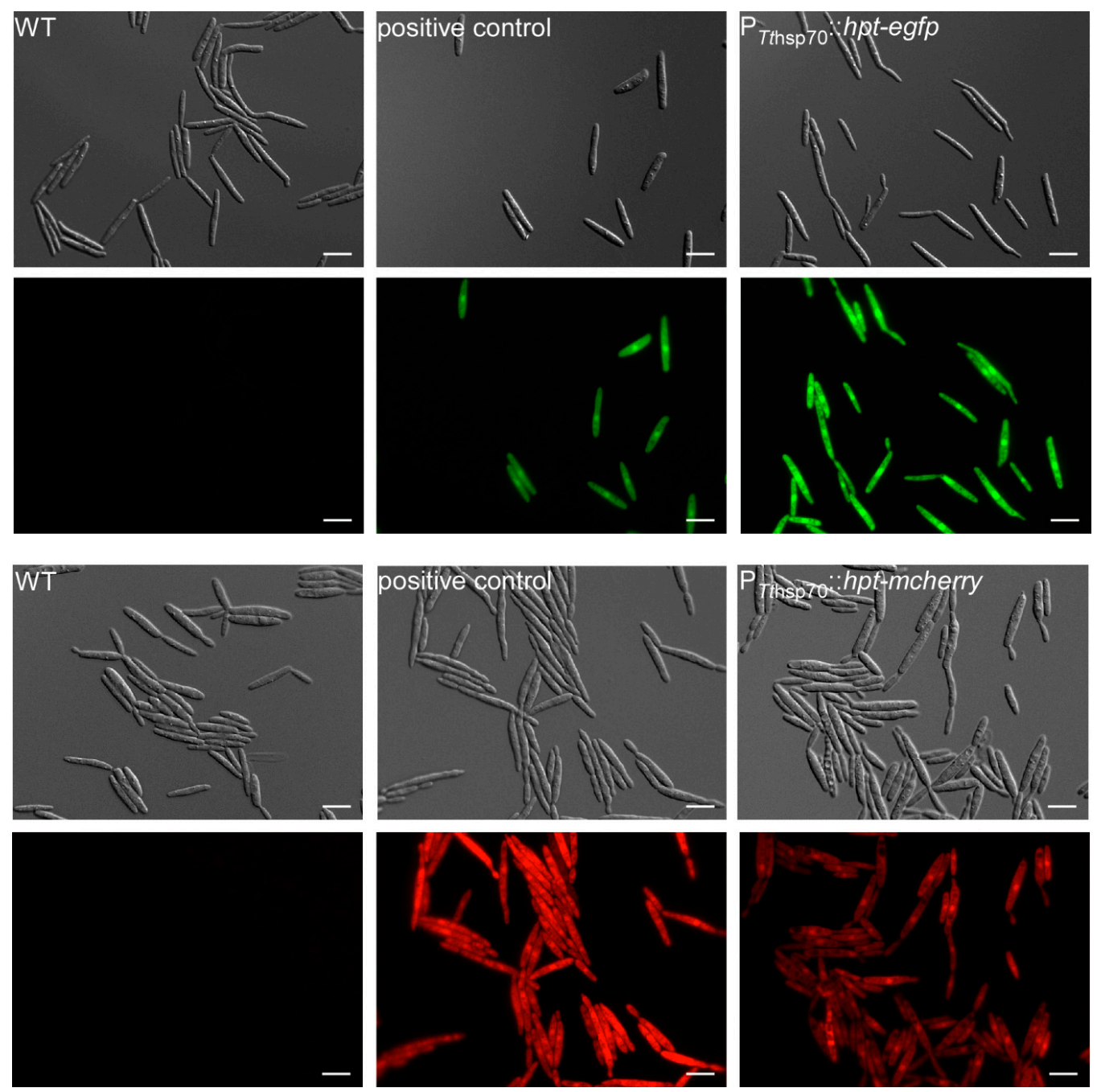

Figure 5. Verification of resistance-reporter constructs in $U$. maydis. Reporter constructs containing a fusion of hygromycinphospho-transferase gene ( $h p t$ ) and the fluorescent marker (egfp or mcherry) under the control of $h s p 70$ promoter and terminator regions derived from the T. thlaspeos genome were tested in $U$. maydis. Upon transformation of the linearized construct, it randomly integrates into the genome. Protein accumulation was visualized by the green/red fluorescence. The eGfp expression under the promoter region of T. thlaspeos was stronger than compared to the stably integrated construct under the control of a strong, synthetic promoter (Potef). This confirms that the fusion protein is active. In comparison, mcherry-fluorescence in the strain carrying the Tthsp70 promoter was weaker than the stably integrated construct under the control of the Potef promoter. Scale bar: $10 \mu \mathrm{m}$.

First, we needed to define which plasmid to use. Therefore, we transformed an equimolar mixture of five hpt-eGfp plasmids with different promoters (Table S2) into T. thlaspeos LF1 protoplasts generated with the optimized method using the standard $U$. maydis conditions for transformation [28]. This resulted in a single transformant which had

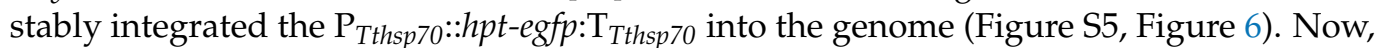
transformations using this plasmid regularly result in fluorescent transformants. Based on this successful transformation, a $\mathrm{P}_{\text {Tthsp70 }}:$ hpt-mcherry: $\mathrm{T}_{\text {Tthsp } 70}$ construct was generated (Table S2), tested in U. maydis (Figure 5), and transformed into T. thlaspeos LF2 (Figure 6), showing that compatible mating partners of $T$. thlaspeos can be tagged with different reporters to follow the mating process. 

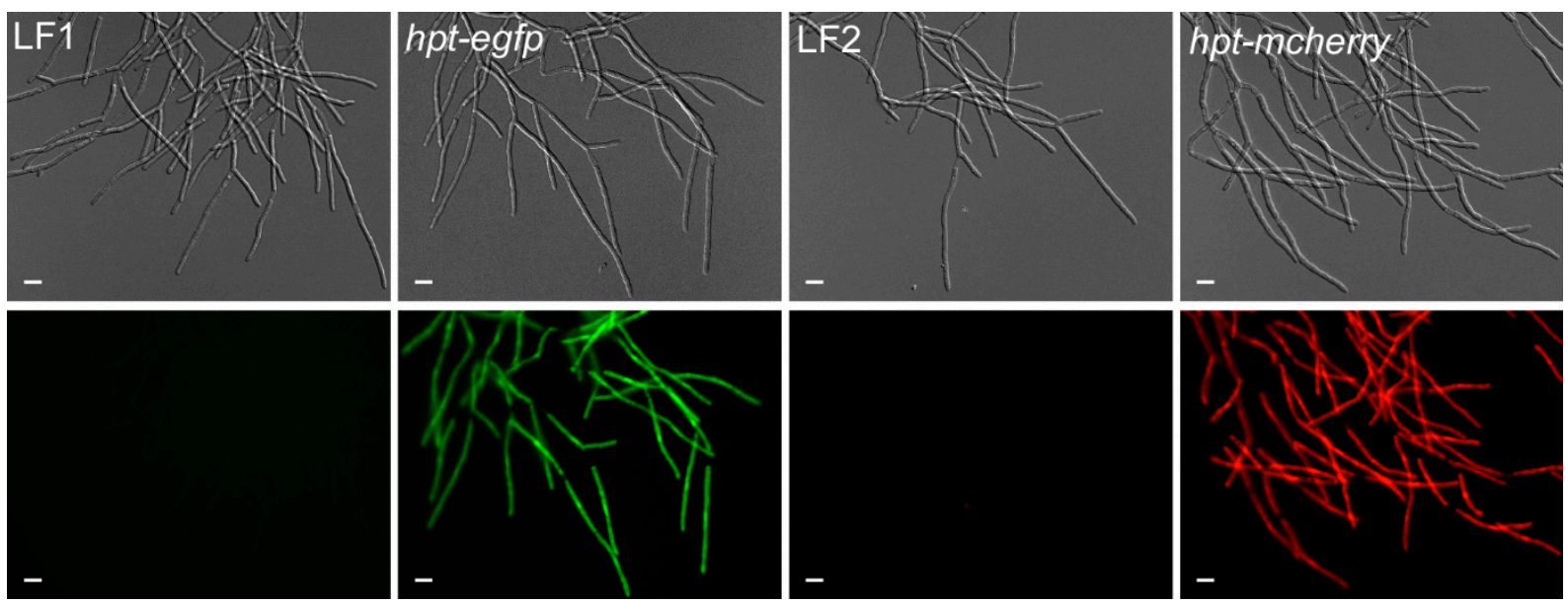

Figure 6. Generation of reporter lines in T. thlaspeos. Reporter constructs containing the active fusion of the hygromycinphospho-transferase gene ( $h p t$ ) and the fluorescent marker (egfp or mcherry) under the control of the strong hsp70 promoter from T. thlaspeos were transformed into the cultures T. thlaspeos LF1 or LF2, respectively. Fluorescent signals accumulate in the cytosol of all cells. Strains: hpt-egfp: LF1_P $P_{\text {Ths } p 70}:$ :hpt-egfp, and hpt-mcherry: LF2_P ${ }_{\text {Tthsp } 70}:$ hpt-mcherry. Scale bar: $10 \mu \mathrm{m}$.

One key aspect for gene targeted manipulations is efficient homologous recombination. To test whether T. thlaspeos reaches the same high rates of up to $50 \%$ as $U$. maydis, we targeted the pheromone receptor gene pra1 in the T. thlaspeos LF1 background for deletion. The construct design was based on $U$. maydis with $1 \mathrm{~kb}$ flanking sequences [27]. Transformation of the construct resulted in 122 candidates on the transformation plates. Reselection of 19 candidates on fresh hygromycin plates led to only nine candidates that remained resistant. The other candidates were either false positives, or they only transiently expressed the resistance protein. These are not interesting for stable integration. In subsequent analysis of the nine candidates, successful deletion of the pra1 locus was confirmed for two transformants (Figure S5), giving a homologous recombination rate of $22 \%$.

In summary, we have now adapted the protoplast-mediated transformation for the filamentously growing Brassicaceae smut fungus T. thlaspeos. Together, with its ability for efficient homologous recombination, this gives us a tool to study plant-microbe interactions of smut fungi in the model plant $A$. thaliana with two genetically tractable partners.

\subsection{Mating of Filaments}

When T. thlaspeos teliospores germinate, they give rise to an infectious filament that can directly penetrate the plant. On the other hand, these filaments also can give rise to haploid culture. Our haploid cultures T. thlaspeos LF1 and LF2 have compatible mating types. They can fuse at the tip and form a new filament [15]. To visualize directional growth of compatible LF1 and LF2 hyphae towards each other during mating, we carried out confrontation experiments. In close proximity, LF1 and LF2 hyphae sense each other, and reorient their growth to meet (Figure 7A). In some cases, some hyphae return their growth in direction towards the compatible filament after initial passage. Upon contact, they fuse and result in a new filament (Figure 7A,B, Video S1). To prove that fused hyphae really share a common cytoplasm, mating was also observed in cocultivation experiments of compatible strains expressing eGfp and mCherry (Figure 7C). After hyphal fusion, eGfp and mCherry fluorescence could be observed in one cytoplasmic segment indicative of plasmogamy. On the other hand, if the pheromone receptor Pra1 is deleted, hyphae of compatible strains grow directly past each other without hyphal fusion (Figure 7A,B and Video S2). These findings confirm that the pheromone-receptor system in T. thlaspeos [15] is active and initiates mating. In the future, the generation of nuclei-reporter-strains with 
NLS-fusion-constructs will allow tracking of the nuclei and thereby the investigation of karyogamy during mating.

A
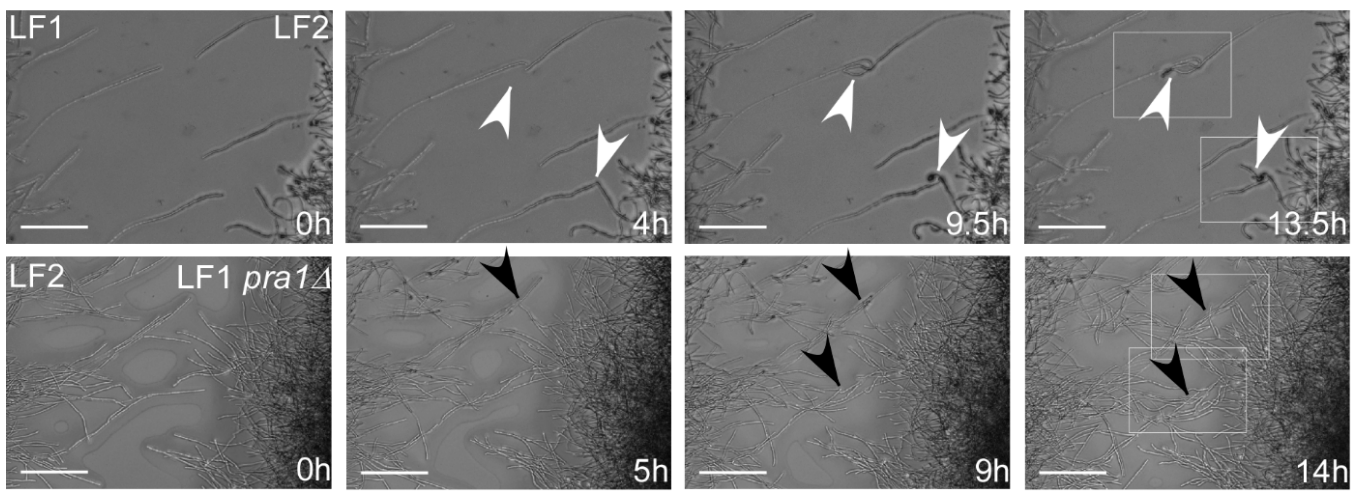

B
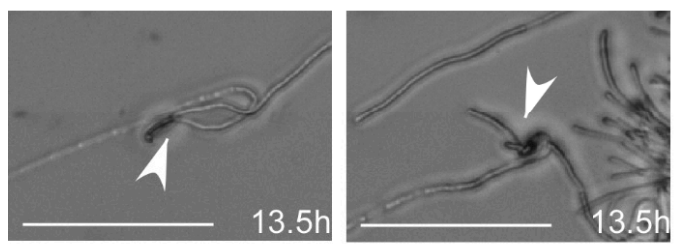

C
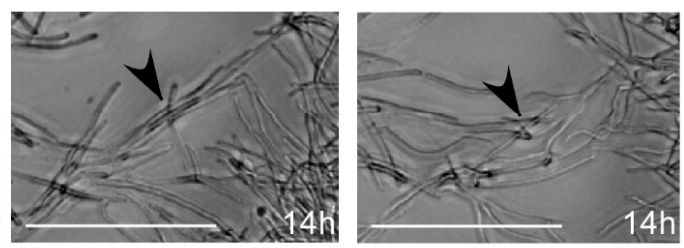

D


Figure 7. Mating in T. thlaspeos. (A) Top: Confrontation assay of mating partners $m f a 1 / p r a 1$ (LF1) or $m f a 2 / p r a 2$ (LF2). Over the course of 13.5 hours, several mating events of LF1 and LF2 were observed. White arrowheads mark the fusion event. Bottom: Confrontation assay of LF1 pra1 $\Delta$ and LF2. Over the course of $14 \mathrm{~h}$, hyphae did not mate. Two spots where hyphae could no longer sense each other and cross are marked with black arrow heads. Scale bar: $25 \mu \mathrm{m}$. (B,C) Magnification of the mating and crossing events from the white boxes marked in (A). Scale bar: $100 \mu \mathrm{m}$. (D) Liquid mating assay with mating partners expressing either cytoplasmic eGfp (LF1-eGfp) or mCherry (LF2-mCherry). Fused hyphae express both eGfp and mCherry and appear yellow in the merged picture (white arrowhead). Scale bar: $25 \mu \mathrm{m}$.

\section{Discussion}

When we first set out to work with $T$. thlaspeos, our aim was to establish a genetically tractable smut fungus in a model host plant such as A. thaliana [15]. An important aim for reaching this goal was genetic manipulation. Here, we show that like other smut fungi, T. thlaspeos is amenable to protoplast-mediated transformation. We have generated a hygromycin resistance cassette, where expression of the hygromycin-phospho-transferase, hpt, is controlled by the T. thlaspeos hsp 70 promoter sequence, similar to the cassettes used in $U$. maydis [3]. Interestingly, promoter sequences seem to be exchangeable between smut fungi, since the $T$. thlaspeos promoters were active in $U$. maydis and several groups have 
successfully used $U$. maydis constructs $[23,45]$. This now enables us to generate reporter strains for a broad range of scientific questions.

Most important to establishing a successful protoplasting protocol is the choice of the lytic enzyme(s). The fungal cell wall is a multilayered, chemically complex structure consisting mainly of polysaccharides and varying amounts of lipids, proteins, and polyphosphates [46]. Its composition is not only variable between species [30], but also highly dependent on the culture conditions [47] and morphology [48]. In our case, the combined activity of Yatalase and Glucanex was necessary for efficient digestion of the $T$. thlaspeos cell wall, although they appear to have overlapping enzymatic properties. Similar additive effects have recently been shown for the ascomycete Hirsutella sinensis [49] and Ag. aegerita [31]; while in Cordyceps militaris, the enzymes mix is less active than Glucanex alone [50]. Hence, during the establishment of conditions for protoplasting, various lytic enzymes and combinations should be tested to reach optimal cell wall degradation [30]. Moreover, commercial manufacturing of enzymes can be stopped, with the broadly used Novozyme 234 being a recent example. Hence, the identification of suitable enzymes can be a reoccurring problem even for established protocols.

The second important factor is the osmotic stabilizer, because it depends on the choice of the protoplasting enzyme. For example, the enzymatic activity of Yatalase is inhibited by sorbitol and sucrose. In the 1970s, similar observations were made for helicase [35] and snail enzyme [34]. Protoplasting protocols with Yatalase use inorganic salts as osmotic stabilizer [21,31,37,40,51] and similar to these old reports, for T. thlaspeos, we now use $\mathrm{MgSO}_{4}$ to enable cell wall degradation.

Together with other factors influencing the protoplast formation, such as growth conditions of the culture, buffer composition, $\mathrm{pH}$, temperature, or protoplasting time, establishing new transformation protocols quickly becomes a multi-factorial challenge, and testing full-factorial replicates is time-consuming and costly. For T. thlaspeos, we designed pilot studies covering selected combinations in single replicates based on existing transformation protocols, and used the most promising buffer, osmotic stabilizer, and enzyme combination for further optimization. While this approach does not cover all combinations, it allowed us to establish a good transformation protocol with reasonable effort.

As a proof-of-principle for our transformation protocol, we investigated the wellcharacterized smut fungal mating process in T. thlaspeos. In the first step, we generated reporter strains expressing cytosolic eGfp or mCherry to visualize the fusion of hyphae. The resulting filaments express both eGfp and mCherry, indicative of a common cytoplasm, as typical for the dikaryotic smut fungi [52,53]. Next, we looked into dependency on the pheromone receptor. To this end, we generated a deletion mutant of the pheromone receptor pra1 [15] based on the strategy of $U$. maydis [28]. Notably, homologous recombination also takes place in T. thlaspeos, so we can modify genes in the haploid culture background easily.

T. thlaspeos pra1 deletion mutants cannot mate anymore. This finding is especially interesting since it is not yet known whether mating is required for T. thlaspeos to fulfil its life cycle. Infectious filaments emerge directly from germinating $T$. thlaspeos teliospores. By contrast, teliospore germination of grass smut fungi gives rise to yeast-like sporidia. Subsequent pathogenic development depends on the morphological switch from yeast to filamentous growth brought about by mating [52]. However, the functional conservation of mating genes in T. thlaspeos suggests an evolutionary-conserved, and therefore important, role of mating also in this fungus [15]. This raises several questions. Is mating necessary for the lifecycle of $T$. thlaspeos? Where and when does mating occur? When do T. thlaspeos hyphae undergo meiosis? Is the filament emerging from the teliospore diploid or dikaryotic? Is the transition to haploid hyphae also occurring naturally in this state of the lifecycle? With the established transformation protocol, we will be able to further address these questions. This will shed light not only onto the mating process of T. thlaspeos, but also on the role of RNA communication in virulence, perennial persistence of the fungus in planta, and nutrition of a smut fungus during biotrophic growth. 


\section{Conclusions}

Establishing the genetic manipulation of the Brassicaceae smut fungus T. thlaspeos now allows us to generate reporter strains as well as targeted deletions or modifications of fungal genes. Combined with the fungal colonization of the model plant $A$. thaliana, we thereby provide a pathosystem, in which both partners have a small, genetically tractable genome for addressing the current and future questions of plant-microbe interactions.

Supplementary Materials: The following are available online at https:/ / www.mdpi.com/2309-6 08X/7/1/38/s1, Figure S1: buffer_comparison, Figure S2: antibiotics, Figure S3: cbx_alignment, Figure S4: transformation_constructs_in_U_maydis, Figure S5: Molecular confirmation of reporter and mutant strains, Table S1: protoplasting_pilot, Table S2: transformation constructs, Video S1: LF1+LF2_confrontation_experiment, Video S2: LF2+LF1-pra1 $\Delta$ _confrontation_experiment, Protocol S1: Plasmid generation, and Protocol S2: Protoplasts and transformation of Thecaphora thlaspeos.

Author Contributions: Conceptualization, V.G.; investigation, L.P., K.B., L.G., and P.H.; writingoriginal draft preparation, L.P. and V.G.; writing-review and editing, V.G.; visualization, L.P.; supervision, V.G.; project administration, V.G.; funding acquisition, V.G. All authors have read and agreed to the published version of the manuscript.

Funding: Research in the laboratory of VG was funded by the Deutsche Forschungsgemeinschaft (DFG, German Research Foundation) under Germany's Excellence Strategy (EXC-2048/1, project ID 390686111); the International Research Training NEXTplant (DFG, project ID 391465903/GRK 2466); and the Bioeconomy Science Center (BioSC), which is financially supported by the Ministry of Innovation, Science, and Research within the framework of the NRW Strategieprojekt BioSC (No. 313/323-400-00213).

Institutional Review Board Statement: Not applicable.

Informed Consent Statement: Not applicable.

Data Availability Statement: The data presented in this study are available in this manuscript and constructs can be requested from the corresponding author.

Acknowledgments: We are grateful to T. Langner, M. Ötztürk, and J. Darenberg for support with cloning of the constructs. R. Kellner helped with discussion and ideas during the development of the transformation protocol. L. Lange provided plates with regenerating protoplasts for microscopy, and K. Vogel supported microscopy. In addition, we would like to thank C. Haag for critically reading the manuscript, $M$. Feldbrügge for discussions, support, and encouragement throughout the establishment of the method, and P. Künzel for support with preparing the movie files.

Conflicts of Interest: The authors declare no conflict of interest. The funders had no role in the design of the study; in the collection, analyses, or interpretation of data; in the writing of the manuscript, or in the decision to publish the results.

\section{References}

1. Kronstad, J.W. Pathogenesis and sexual development of the smut fungi. In Plant-Microbe Interactions; Stacey, G.K.N.T., Ed.; Springer: Boston, MA, USA, 1997; Volume 1.

2. Feldbrügge, M.; Kämper, J.; Steinberg, G.; Kahmann, R. Regulation of mating and pathogenic development in Ustilago maydis. Curr. Opin. Microbiol. 2004, 7, 666-672. [CrossRef] [PubMed]

3. Brachmann, A.; König, J.; Julius, C.; Feldbrügge, M. A reverse genetic approach for generating gene replacement mutants in Ustilago maydis. Mol. Genet. Genom. 2004, 272, 216-226. [CrossRef] [PubMed]

4. Banuett, F. Ustilago maydis, the delightful blight. Trends Genet. 1992, 8, 174-180. [CrossRef]

5. Vollmeister, E.; Schipper, K.; Baumann, S.; Haag, C.; Pohlmann, T.; Stock, J.; Feldbrügge, M. Fungal development of the plant pathogen Ustilago maydis. Fems. Microbiol. Rev. 2012, 36, 59-77. [CrossRef] [PubMed]

6. Lanver, D.; Tollot, M.; Schweizer, G.; Lo Presti, L.; Reissmann, S.; Ma, L.S.; Schuster, M.; Tanaka, S.; Liang, L.; Ludwig, N.; et al. Ustilago maydis effectors and their impact on virulence. Nat. Rev. Microbiol. 2017, 15, 409-421. [CrossRef] [PubMed]

7. Bölker, M.; Urban, M.; Kahmann, R. The a mating type locus of $U$. maydis specifies cell signaling components. Cell 1992, 68, 441-450. [CrossRef]

8. Gillissen, B.; Bergemann, J.; Sandmann, C.; Schroeer, B.; Bölker, M.; Kahmann, R. A 2-component regulatory system for self non-self recognition in Ustilago maydis. Cell 1992, 68, 647-657. [CrossRef] 
9. García-Muse, T.; Steinberg, G.; Pérez-Martín, J. Pheromone-induced $\mathrm{G}_{2}$ arrest in the phytopathogenic fungus Ustilago maydis. Eukaryot. Cell 2003, 2, 494. [CrossRef]

10. Kellner, R.; Vollmeister, E.; Feldbrugge, M.; Begerow, D. Interspecific sex in grass smuts and the genetic diversity of their pheromone-receptor system. PLoS Genet 2011, 7. [CrossRef]

11. Toh, S.S.; Perlin, M.H. Resurgence of less-studied smut fungi as models of phytopathogenesis in the Omics age. Phytopathology 2016, 106, 1244-1254. [CrossRef]

12. Vanky, K.; Lutz, M.; Bauer, R. About the genus Thecaphora (Glomosporiaceae) and its new synonyms. Mycol. Prog. 2008, 7, 31-39. [CrossRef]

13. Andrade, O.; Munoz, G.; Galdames, R.; Duran, P.; Honorato, R. Characterization, in vitro culture, and molecular analysis of Thecaphora solani, the causal agent of potato smut. Phytopathology 2004, 94, 875-882. [CrossRef] [PubMed]

14. Conforto, C.; Cazón, I.; Fernández, F.D.; Marinelli, A.; Oddino, C.; Rago, A.M. Molecular sequence data of Thecaphora frezii affecting peanut crops in Argentina. Eur. J. Plant Pathol. 2013, 137, 663-666. [CrossRef]

15. Frantzeskakis, L.; Courville, K.J.; Pluecker, L.; Kellner, R.; Kruse, J.; Brachmann, A.; Feldbrügge, M.; Göhre, V. The plant-dependent life cycle of Thecaphora thlaspeos: A smut fungus adapted to Brassicaceae. Mol. Plant-Microbe Interact. 2017, 30, 271-282. [CrossRef] [PubMed]

16. Courville, K.J.; Frantzeskakis, L.; Gul, S.; Haeger, N.; Kellner, R.; Heßler, N.; Day, B.; Usadel, B.; Gupta, Y.K.; van Esse, H.P.; et al. Smut infection of perennial hosts: The genome and the transcriptome of the Brassicaceae smut fungus Thecaphora thlaspeos reveal functionally conserved and novel effectors. New Phytol. 2019, 222, 1474-1492. [CrossRef] [PubMed]

17. Wang, J.; Holden, D.W.; Leong, S.A. Gene transfer system for the phytopathogenic fungus Ustilago maydis. Proc. Natl. Acad. Sci. USA 1988, 85, 865-869. [CrossRef] [PubMed]

18. Schirawski, J.; Heinze, B.; Wagenknecht, M.; Kahmann, R. Mating type loci of Sporisorium reilianum: Novel pattern with three a and multiple b specificities. Eukaryot. Cell 2005, 4, 1317-1327. [CrossRef] [PubMed]

19. Cervantes-Chavez, J.A.; Ali, S.; Bakkeren, G. Response to environmental stresses, cell-wall integrity, and virulence are orchestrated through the calcineurin pathway in Ustilago hordei. Mol. Plant-Microbe Interact. 2011, 24, 219-232. [CrossRef]

20. Yu, J.; Zhang, Y.; Cui, H.; Hu, P.; Yu, X.; Ye, Z. An efficient genetic manipulation protocol for Ustilago esculenta. FEMS Microbiol. Lett. 2015, 362. [CrossRef]

21. Rabe, F.; Bosch, J.; Stirnberg, A.; Guse, T.; Bauer, L.; Seitner, D.; Rabanal, F.A.; Czedik-Eysenberg, A.; Uhse, S.; Bindics, J.; et al. A complete toolset for the study of Ustilago bromivora and Brachypodium sp as a fungal-temperate grass pathosystem. Elife 2016, 5. [CrossRef]

22. Zuccaro, A.; Basiewicz, M.; Zurawska, M.; Biedenkopf, D.; Kogel, K.-H. Karyotype analysis, genome organization, and stable genetic transformation of the root colonizing fungus Piriformospora indica. Fungal Genet. Biol. 2009, 46, 543-550. [CrossRef] [PubMed]

23. Cheng, Y.; Belzile, F.; Tanguay, P.; Bernier, L.; Bélanger, R. Establishment of a gene transfer system for Pseudozyma flocculosa, an antagonistic fungus of powdery mildew fungi. Mol. Genet. Genom. 2001, 266, 96-102. [CrossRef] [PubMed]

24. Lu, S.; Shen, X.; Chen, B. Development of an efficient vector system for gene knock-out and near in-cis gene complementation in the sugarcane smut fungus. Sci. Rep. 2017, 7, 3113. [CrossRef] [PubMed]

25. Ali, S.; Laurie, J.D.; Linning, R.; Cervantes-Chávez, J.A.; Gaudet, D.; Bakkeren, G. An immunity-triggering effector from the barley smut fungus Ustilago hordei resides in an ustilaginaceae-specific cluster bearing signs of transposable element-assisted evolution. PLoS Pathog. 2014, 10, e1004223. [CrossRef]

26. Ji, L.; Jiang, Z.D.; Liu, Y.; Koh, C.M.; Zhang, L.H. A simplified and efficient method for transformation and gene tagging of Ustilago maydis using frozen cells. Fungal Genet. Biol. 2010, 47, 279-287. [CrossRef] [PubMed]

27. Terfrüchte, M.; Joehnk, B.; Fajardo-Somera, R.; Braus, G.H.; Riquelme, M.; Schipper, K.; Feldbrügge, M. Establishing a versatile Golden Gate cloning system for genetic engineering in fungi. Fungal Genet. Biol. 2014, 62, 1-10. [CrossRef] [PubMed]

28. Bösch, K.; Frantzeskakis, L.; Vraneš, M.; Kämper, J.; Schipper, K.; Göhre, V. Genetic manipulation of the plant pathogen Ustilago maydis to study fungal biology and plant microbe interactions. J. Vis. Exp. 2016, 115. [CrossRef]

29. Langner, T.; Özturk, M.; Hartmann, S.; Cord-Landwehr, S.; Moerschbacher, B.; Walton, J.D.; Göhre, V. Chitinases Are Essential for Cell Separation in Ustilago maydis. Eukaryot. Cell 2015, 14, 846-857. [CrossRef]

30. Li, D.; Tang, Y.; Lin, J.; Cai, W. Methods for genetic transformation of filamentous fungi. Microb. Cell Factories 2017, 16, 168. [CrossRef]

31. Herzog, R.; Solovyeva, I.; Bölker, M.; Lugones, L.G.; Hennicke, F. Exploring molecular tools for transformation and gene expression in the cultivated edible mushroom Agrocybe aegerita. Mol. Genet. Genom. 2019, 294, 663-677. [CrossRef]

32. de Bekker, C.; Wiebenga, A.; Aguilar, G.; Wösten, H.A.B. An enzyme cocktail for efficient protoplast formation in Aspergillus niger. J. Microbiol. Methods 2009, 76, 305-306. [CrossRef]

33. Ruiz-Díez, B. Strategies for the transformation of filamentous fungi. J. Appl. Microbiol. 2002, 92, 189-195. [CrossRef]

34. Arnold, W.N.; Garrison, R.G. Isolation and characterization of protoplasts from Saccharomyces rouxii. J. Bacteriol. 1979, 137, 1386-1394. [CrossRef]

35. Sietsma, J.H.; De Boer, W.R. Formation and regeneration of protoplasts from Pythium PRL 2142. Microbiology 1973, 74, $211-217$. [CrossRef] 
36. Tilburn, J.; Scazzocchio, C.; Taylor, G.G.; Zabicky-Zissman, J.H.; Lockington, R.A.; Davies, R.W. Transformation by integration in Aspergillus nidulans. Gene 1983, 26, 205-221. [CrossRef]

37. Hu, Y.; Dietrich, D.; Xu, W.; Patel, A.; Thuss, J.A.J.; Wang, J.; Yin, W.-B.; Qiao, K.; Houk, K.N.; Vederas, J.C.; et al. A carbonateforming Baeyer-Villiger monooxygenase. Nat. Chem. Biol. 2014, 10, 552-554. [CrossRef]

38. De Vries, O.M.H.; Wessels, J.G.H. Release of protoplasts from Schizophyllum commune by a lytic enzyme preparation from Trichoderma viride. Microbiology 1972, 73, 13-22. [CrossRef]

39. Ferrer, S.; Ramón, D.; Salom, J.; Vicente, E.; Uruburu, F. Protoplasts from Podospora anserina: Isolation, purification, and transformation. Curr. Microbiol. 1985, 12, 301-306. [CrossRef]

40. Zheng, Y.-M.; Lin, F.-L.; Gao, H.; Zou, G.; Zhang, J.-W.; Wang, G.-Q.; Chen, G.-D.; Zhou, Z.-H.; Yao, X.-S.; Hu, D. Development of a versatile and conventional technique for gene disruption in filamentous fungi based on CRISPR-Cas9 technology. Sci. Rep. 2017, 7, 9250. [CrossRef]

41. Eidtmann, A.; Schauz, K. Cryopreservation of protoplasts from sporidia of Ustilago maydis. Mycol. Res. 1992, 96, 318-320. [CrossRef]

42. $\quad$ van Peer, A.F.; de Bekker, C.; Vinck, A.; Wösten, H.A.B.; Lugones, L.G. Phleomycin increases transformation efficiency and promotes single integrations in Schizophyllum commune. Appl. Environ. Microbiol. 2009, 75, 1243-1247. [CrossRef]

43. Keon, J.P.R.; Broomfield, P.L.E.; White, G.A.; Hargreaves, J.A. A mutant form of the succinate dehydrogenase iron-sulphur protein subunit confers resistance to carboxin in the maize smut pathogen Ustilago maydis. Biochem. Soc. Trans. 1994, $22,234-237$. [CrossRef]

44. Lai, J.; Ng, S.K.; Liu, F.F.; Patkar, R.N.; Lu, Y.; Chan, J.R.; Suresh, A.; Naqvi, N.; Jedd, G. Marker fusion tagging, a new method for production of chromosomally encoded fusion proteins. Eukaryot. Cell 2010, 9, 827-830. [CrossRef]

45. Ghareeb, H.; Zhao, Y.; Schirawski, J. Sporisorium reilianum possesses a pool of effector proteins that modulate virulence on maize. Mol. Plant Pathol. 2019, 20, 124-136. [CrossRef]

46. Bartnicki-Garcia, S. Cell wall chemistry, morphogenesis, and taxonomy of fungi. Annu. Rev. Microbiol. 1968, 22, 87-108. [CrossRef]

47. Aguilar-Uscanga, B.; François, J.M. A study of the yeast cell wall composition and structure in response to growth conditions and mode of cultivation. Lett. Appl. Microbiol. 2003, 37, 268-274. [CrossRef]

48. Gander, J.E. Fungal cell wall glycoproteins and peptido-polysaccharides. Annu. Rev. Microbiol. 1974, 28, 103-120. [CrossRef]

49. Jin, L.-Q.; Xu, Z.-W.; Men, X.-H.; Bo, Z.; Liu, Z.-Q.; Zheng, Y.-G. Enhancement of protoplast preparation and regeneration of Hirsutella sinensis based on process optimization. Biotechnol. Lett. 2020, 42, 2357-2366. [CrossRef]

50. Lou, H.-W.; Ye, Z.-W.; Yu, Y.-H.; Lin, J.-F.; Guo, L.-Q.; Chen, B.-X.; Tang, H.-B.; Wei, T.; Chen, L.-T.; Yun, F. The efficient genetic transformation of Cordyceps militaris by using mononuclear protoplasts. Sci. Hortic. 2019, 243, 307-313. [CrossRef]

51. Kuwano, T.; Shirataki, C.; Itoh, Y. Comparison between polyethylene glycol- and polyethylenimine-mediated transformation of Aspergillus nidulans. Curr. Genet. 2008, 54, 95-103. [CrossRef]

52. Casselton, L.; Feldbrügge, M. Mating and sexual morphogenesis in Basidiomycete fungi. In Cellular and Molecular Biology of Filamentous Fungi; American Society of Microbiology: Washington, DC, USA, 2010. [CrossRef]

53. Morrow, C.A.; Fraser, J.A. Sexual reproduction and dimorphism in the pathogenic basidiomycetes. FEMS Yeast Res. 2009, 9, 161-177. [CrossRef] [PubMed] 